\title{
The prognostic significance of survivin expression in patients with HNSCC: a systematic review and meta-analysis
}

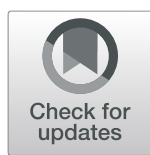

Liu-qing $\mathrm{Zhou}^{1 \dagger}$, Yao Hu${ }^{2+}$ and Hong-jun Xiao ${ }^{1 *}$

\begin{abstract}
Background: Survivin has been recently identified as a promising novel therapeutic target and prognostic marker in different types of cancer. Here we conducted a comprehensive meta-analysis to better clarify they the precise prognostic and diagnostic value of survivin in head and neck squamous cell carcinoma (HNSCC).

Methods: Database of PubMed (Medline), Embase, and Web of Science were systematically searched for related published literature up to September 2020. Pooled hazards ratios (HR) and related 95\% confidence intervals (Cl) were used to estimate the association of survivin expression and survival outcomes in HNSCC patients.

Results: Twenty eight studies with 4891 patients were finally included in this meta-analysis, the pooled analysis indicated that the survivin expression was significantly correlated with poorer overall survival (OS) ( $\mathrm{HR}, 2.02 ; 95 \% \mathrm{Cl}$, $1.65-2.47, P<0.001)$, and poorer disease-free survival (DFS)/ disease-specific survival (DSS) (HR=2.03, 95\%Cl: 1.64$2.52, P<0.001 ; \mathrm{HR}=1.92,95 \% \mathrm{Cl}: 1.41-2.60, P<0.001$, receptively). Similar results were observed in subgroup analysis stratified by different cancer types, such as laryngeal squamous cell carcinoma (LSCC) (HR $=1.35,95 \% \mathrm{Cl}$ : 1.05-1.74, $P<0.001$ ), oral squamous cell carcinomas (OSCC) ( $\mathrm{HR}=2.45,95 \% \mathrm{Cl}$ : 1.89-3.17, $P<0.001)$, nasopharyngeal carcinoma $(\mathrm{NPC})(\mathrm{HR}=2.53,95 \% \mathrm{Cl}: 1.76-3.62, P<0.001)$ and HNSCC $(H R=1.52,95 \% \mathrm{Cl}: 1.25-1.86, P<0.001)$. Furthermore, ethnicity-stratified analysis indicated that survivin was significantly associated with poorer OS among both Asian and Non- Asian HNSCC patients ( $\mathrm{HR}=2.16,95 \% \mathrm{Cl}: 1.76-2.66 ; \mathrm{HR}=1.56,95 \% \mathrm{Cl}: 1.33-1.82$, respectively).
\end{abstract}

Conclusions: Our results suggested that survivin is predictors of worse prognosis in HNSCC patients. Hence, survivin is a potential therapeutic target for HNSCC.

Keywords: Survivin, Head and neck squamous cell carcinoma, Prognosis, Meta-analysis

\section{Introduction}

Head and neck squamous cell carcinoma (HNSCC) is ranking as the sixth most prevalent cancer worldwide [1], they develop from the squamous mucosa of the upper aerodigestive tract, including nasal cavity, nasopharynx, larynx, hypopharynx, oropharynx and so on. Squamous cell carcinoma (SCC) accounts for up to $90 \%$

\footnotetext{
*Correspondence: xhjent_whxh@hust.edu.cn

${ }^{+}$Liu-qing Zhou and Yao Hu contributed equally to this work.

'Department of Otorhinolaryngology, Union Hospital, Ongji Medical College, Huazhong University of Science and Technology, Wuhan 430022, China Full list of author information is available at the end of the article
}

of malignant tumor in the head and neck region. The group of malignancies have similar pathogenesis, staging system, therapeutic strategy, and prognosis despite they arise from different sites of head and neck region, hence, it is rational to classify them into one category, HNSCC [2]. There are several risk factors associated with HNSC C, such as environmental exposures, tobacco use, alcohol consumption and so on [3]. Although the diagnosis and multimodality treatments improved quickly, the 5year survival rate still remains very low due to the complex anatomy of head and neck region [4]. Therefore, it

C C The Author(s). 2021 Open Access This article is licensed under a Creative Commons Attribution 4.0 International License, which permits use, sharing, adaptation, distribution and reproduction in any medium or format, as long as you give appropriate credit to the original author(s) and the source, provide a link to the Creative Commons licence, and indicate if changes were made. The images or other third party material in this article are included in the article's Creative Commons licence, unless indicated otherwise in a credit line to the material. If material is not included in the article's Creative Commons licence and your intended use is not permitted by statutory regulation or exceeds the permitted use, you will need to obtain permission directly from the copyright holder. To view a copy of this licence, visit http://creativecommons.org/licenses/by/4.0/ The Creative Commons Public Domain Dedication waiver (http://creativecommons.org/publicdomain/zero/1.0/) applies to the data made available in this article, unless otherwise stated in a credit line to the data. 
is necessary to identify more reliable new prognostic biomarkers and therapeutic targets.

Survivin, an important member of the inhibitor of apoptosis' (IAP) family, is encoded by baculoviral inverted repeats (BIR) C5 gene [5]. The expression is minimal in normal tissues, however, strong survivin expression is largely observed in numerous cancers [6]. Survivin is an anti-apoptotic factor and regulate intrinsic and extrinsic apoptotic pathways by interacting with many factors. It also plays key roles in cellular stress response by interfering with autophagy. Different proteins of the autophagic machinery, such as Beclin 1, chemokine ligand 2 and light chain 3 interact with survivin [7, 8]. In addition, survivin expression is associate with the process of angiogenesis, it overcomes G2/M phase of the cell cycle and causes mitotic progression in most adults' cancers [9].

Although numerous researches have revealed the association between survivin and the prognosis of HNSCC, the results still remain controversial due to the variance in the sample size, study design, test approach and cutoff value. Therefore, it is essential to clarify the diagnostic and prognostic value of survivin in HNSCC based on the findings from the independently small sample size publications. Here, we searched PubMed (Medline), Embase, and Web of Science databases for relevant publications and undertaken a comprehensive meta-analysis to systematically assess the diagnostic and prognostic role of survivin in HNSCC.

\section{Methods}

\section{Search strategy}

We searched for articles published between 2000 and 2020. Electronic searches for relevant retrieve studies were performed throughout databases, including PubMed (Medline), Web of Science and EMBASE databases in accordance with Dickersin et al. in September 2020 [10]. The retrieval strategy included: (survivin) and (prognosis OR outcome OR mortality OR survival OR progression OR recurrence) and (head and neck or laryngeal or tonsil or oropharyngeal or oral or oropharynx or nasopharyngeal) and (squamous cell cancer or carcinoma). Furthermore, the reference lists of retrieved articles for additional articles were also manually searched. If several studies reported the same patient populations, we enrolled the most complete one to avoid duplication.

\section{Selection criteria}

This meta-analysis was limited to studies about the association between HNSCC and survivin. The inclusion criteria of the meta-analysis were as follows: (1) all patients should be diagnosed with HNSCC; (2) survivin was evaluated in both samples of the HNSCC and normal controls; (3) studies revealed the association between survivin and survival of HNSCC; (4) sufficient statistical analysis was required, including hazard ratios (HR) and their related 95\% confidence interval $(95 \% \mathrm{CI})$ ) for survival outcomes, if not we could calculate them by $p$ values and Kaplan-Meier curves [11] (5) the language of publications was limited to English. The exclusion criteria were: (1) studies without sufficient data for metaanalysis; (2) abstracts, case reports, reviews, letters, expert opinions, etc.; (3) studies about cell lines, in vivo/ vitro studies, and human xenografts. If the same cohort was reported by several studies, the most recent one was included in our study.

\section{Data extraction}

We inspected the duplicates, and removed the repeated papers first. Then, we perused the titles and abstracts of the papers carefully. At last full articles were selected to include the appropriate studies. Two researchers independently evaluated the literature against the inclusion and exclusion criteria (LQ Zhou and Y Hu). Any discrepancy in assessments was resolved by consulting an adjudicating with a third researcher (HJ Xiao). The researchers of the studies were contacted by e-mail to request data or additional information for meta-analytic calculations. The eligible studies for this meta-analysis were reviewed by two reviewers (LQ Zhou and Y Hu) independently. The Newcastle-Ottawa Quality Assessment Scale (NOS) was included to assess the methodological qualities of each publication, a star system (range from 0 to 9) was adopted to evaluate a including publications in three domains, comparability of study groups ( 2 stars), selection of participants (4 stars) and the outcome measurement (3 stars). A study with NOS $\geq 6$ was seemed as a high-quality study $[12,13]$. Reporting recommendations for tumor marker prognostic studies (REMARK), which were developed to address widespread deficiencies in the reporting of such studies, was also applied to evaluate study quality in the present meta-analysis [14]. The REMARK checklist consists of 20 items to report for published tumor marker prognostic studies. They provide a comprehensive overview to educate on good reporting and also provide a valuable reference for the many issues to consider when designing, conducting, and analyzing tumor marker studies and, with minimal adjustment, in prognostic studies in medicine in general.

\section{Statistical analysis}

The HR and the related 95\% CI of survival outcomes were obtained directly from the primary publications or estimated by $p$ values and other published data following Parmer's methods [15]. Statistical heterogeneity among the studies was evaluated using the $\chi^{2}$-based $Q$ test and the $\mathrm{I}^{2}$ statistics [16]. The fixed-effects model was employed for analysis without obvious statistical 
heterogeneity between studies $\left(P>0.10, \quad \mathrm{I}^{2}<50 \%\right)$. Otherwise, the random-effects model was applied. Moreover, we performed subgroup analysis to explore the potential source of heterogeneity. Sensitivity analysis was conducted to investigate the influence of each individual study on the overall pooled results. We used the Begg's and Egger's tests to assess the potential publication bias. We conducted all statistical analyses by STATA statistical software version 15.0 (StataCorp Lp).

\section{Results}

\section{Selection and characteristics of included studies}

A total of 778 potential records were initially identified by searching the electronic databases (Fig. 1). Following exclusion of the duplicates $(n=431)$, reviews, abstracts and letters $(n=25)$ and the studies of irrelevant topics $(n=244), 78$ studies were remained for further assessment by reading their full-text articles. A total of 50 studies did not provide specific data regarding HNSCC or survivin and therefore were excluded. Finally, a total 4891 HNSCC patients in 28 studies with publication years ranging from 2002 to 2019 were enrolled in the present meta-analysis.

The characteristics of the eligible studies were summarized in Table 1. The participants were from China, Tunisia, Turkey, Germany, Italy, Australia, Canada, South Korea, Sweden and Slovenia. Immunohistochemistry (IHC) and/or reverse-transcription polymerase chain reaction (RT-PCR) were used to analysis the survivin protein and/or mRNA expression in the including studies. The characters of antibodies in different studies are summarized in Table S1. They have different clones, dilutions, sources and positive signals. Different PCR instruments were also used in different studies. Our metaanalysis including eight studies for laryngeal squamous cell carcinoma (LSCC), ten studies for oral squamous cell carcinomas (OSCC), five studies for head and neck squamous cell carcinoma (HNSCC) and five studies for nasopharyngeal carcinoma (NPC). Fifteen publications included > 100 patients and 13 publications enrolled < 100 patients, twenty one studies including a total of 3036 patients reported overall survival (OS), nine studies including a total of 925 patients reported disease-free survival (DFS) and three studies including a total of 1485 patients reported disease-specific survival (DSS). The HR and 95\% CI were directly reported in fifteen studies and were estimated in thirteen studies in the original literature. All of the publications' NOS scores were above 6 and the REMARK scores were between 11 and 15.

\section{Association between survivin and survival outcomes of HNSCC patients}

A total of twenty one studies in the present analysis examined the association between survivin and the OS of in HNSCC patients. The heterogeneity among the publications in our study was significant for $\mathrm{Q}$ test $(P<0.1)$. Hence, the random-effects model was adopted and subgroup analysis was used to seek for the potential causes of heterogeneity. The results of these studies indicated expression of survivin were associated with poorer OS (HR, 2.02; 95\% CI, 1.65-2.47, $P<0.001$ ). Medium heterogeneity was noted $\left(I^{2}=50.3 \%, P_{\text {heterogeneity }}=0.005\right)$ (Fig. 2). Nine studies examined the association between

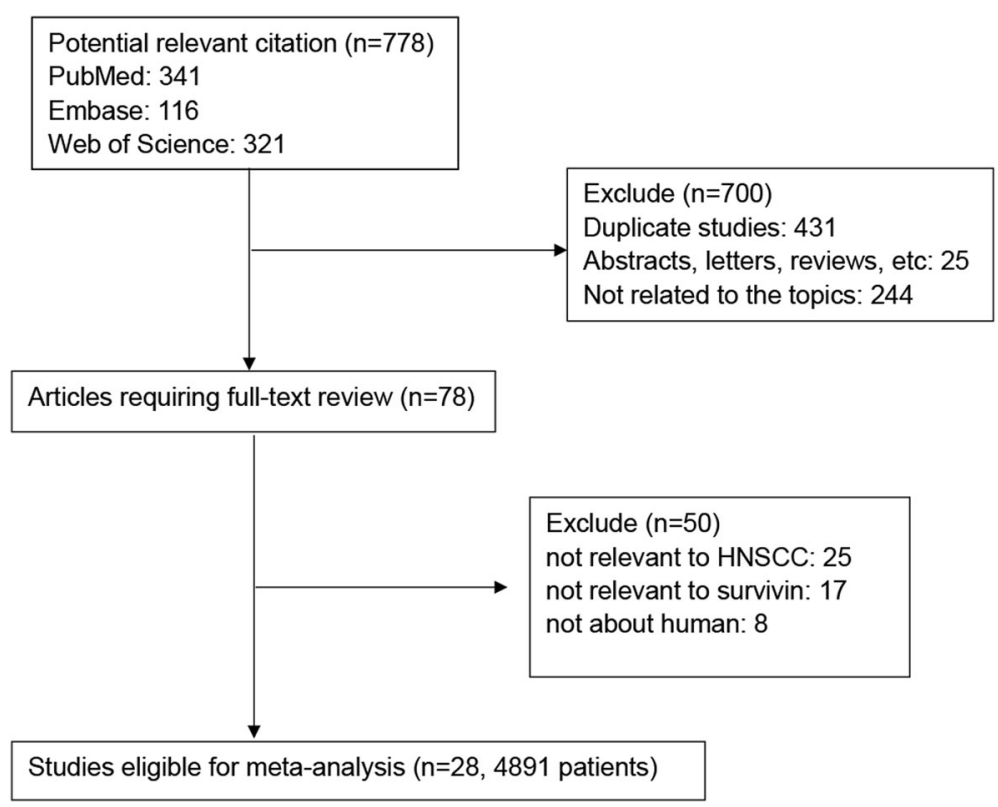

Fig. 1 Flow diagram of the selection of relevant studies included in the meta-analysis 


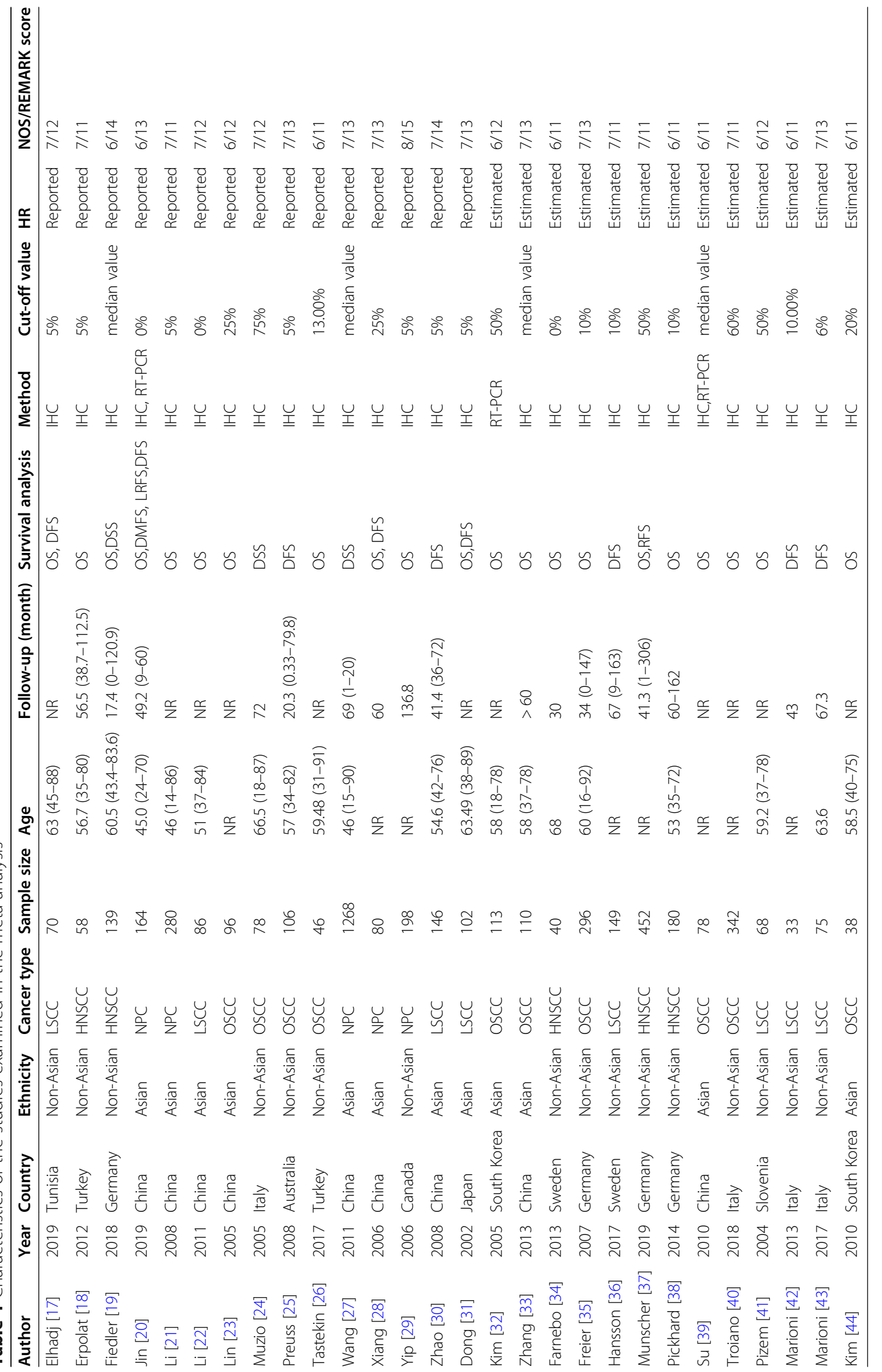




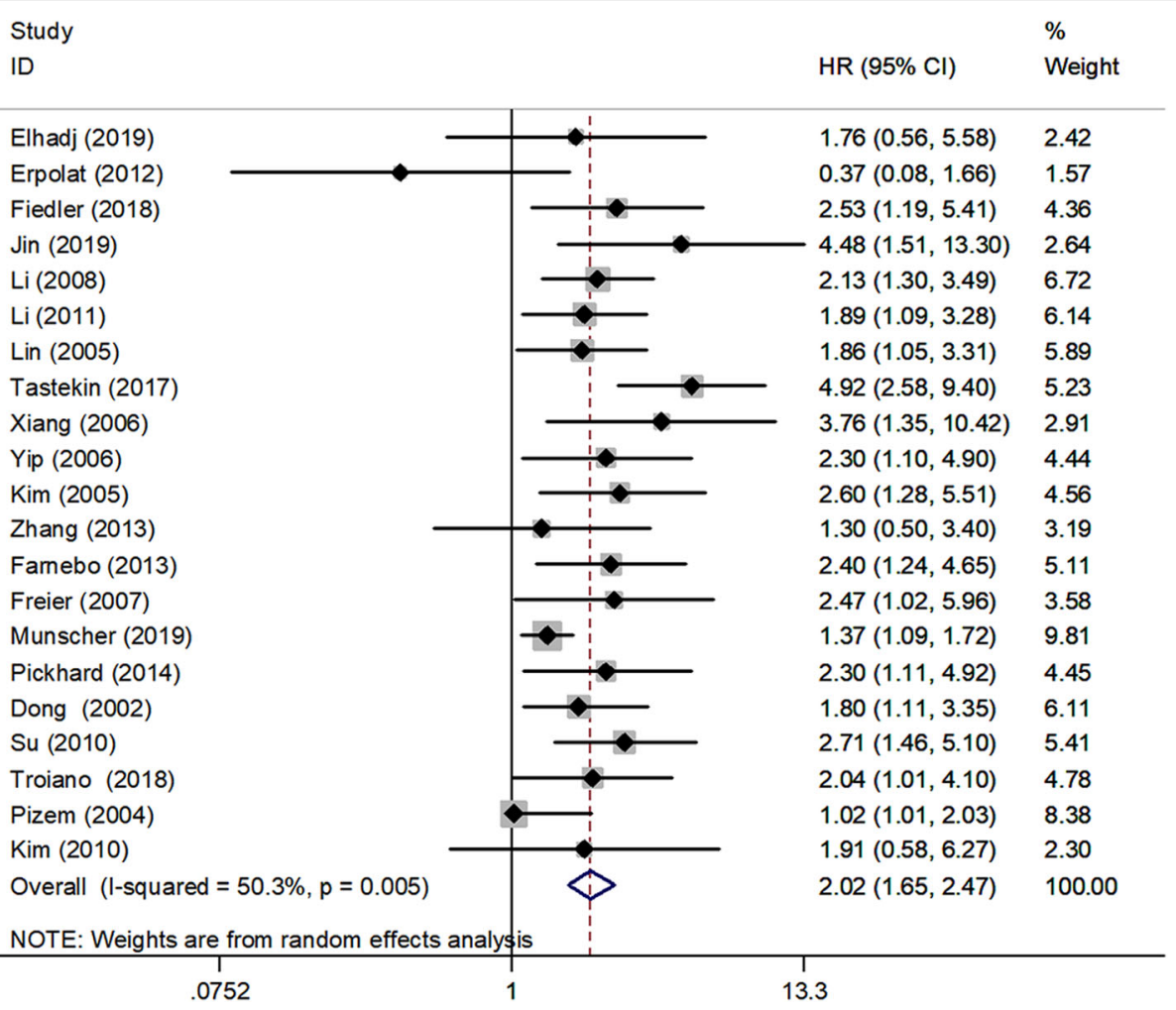

Fig. 2 Forest plot indicating the association between survivin expression and OS in HNSCC

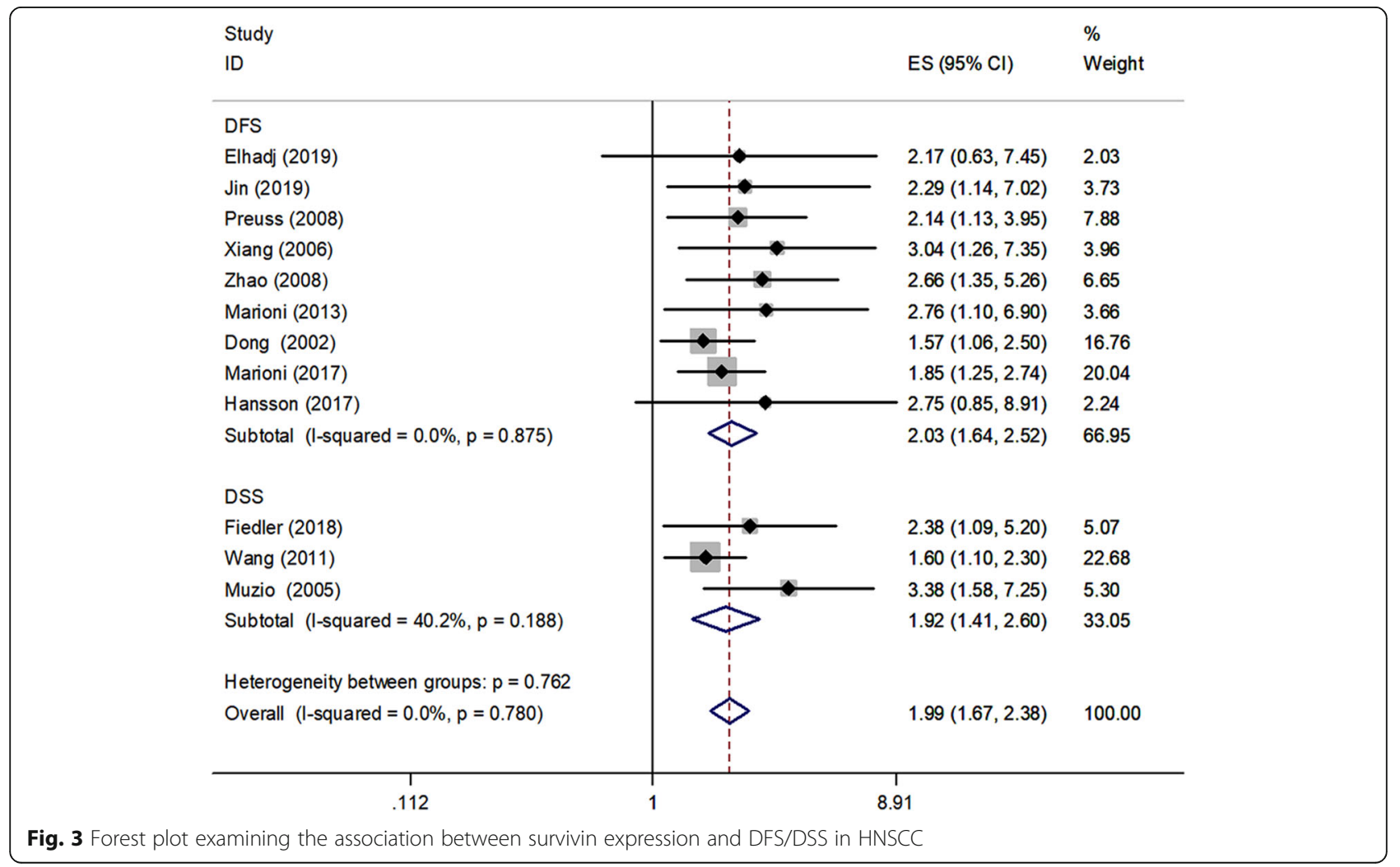


survivin and the DFS and three studies examined the association between survivin and the DSS in HNSCC patients. Figure 3 summarized $\mathrm{HR}$ for $\mathrm{DFS}(\mathrm{HR}=2.03,95 \% \mathrm{CI}$ : 1.64-2.52) and DSS ( $\mathrm{HR}=1.92,95 \% \mathrm{CI}: 1.41-2.60)$, and there was no significant heterogeneity noted between survivin expression and DFS $\left(\mathrm{I}^{2}=0.0 \%, \mathrm{P}_{\text {heterogeneity }}=0.875\right)$, low heterogeneity was noted between survivin expression and DSS $\left(\mathrm{I}^{2}=40.2 \%, \mathrm{P}_{\text {heterogeneity }}=0.188\right)$.

\section{Subgroup analysis for OS was also performed and was stratified according to different cancer types or geographic populations}

Cancer-stratified analysis showed that the summarized HR for LSCC was 1.35 (95\% CI, 1.05-1.74, $P<0.001$ ) with low heterogeneity $\left(I^{2}=42.3 \%, P_{\text {heterogeneity }}=0.158\right)$; for HNSCC was $1.52(95 \%$ CI, $1.25-1.86, P<0.001)$ with medium heterogeneity $\left(\mathrm{I}^{2}=55.3 \%, \mathrm{P}_{\text {heterogeneity }}=0.062\right)$; for NPC was 2.53 (95\% CI, 1.76-3.62, $P<0.001)$ with no significant heterogeneity $\left(\mathrm{I}^{2}=0.0 \%, \mathrm{P}_{\text {heterogeneity }}=0.540\right)$ and for OSCC was 2.45 (95\% CI, 1.89-3.17, $P<0.001$ ) with no significant heterogeneity $\left(\mathrm{I}^{2}=7.7 \%\right.$, $\mathrm{P}_{\text {heterogene- }}$ ity $=0.370)($ Fig. 4).
Ethnicity-stratified analysis demonstrated that the summarized HR for Non-Asian HNSCC patients was 1.56 (95\% CI, 1.33-1.82, $P<0.001$ ) with medium heterogeneity $\left(\mathrm{I}^{2}=68.4 \%\right.$, $\left.\mathrm{P}_{\text {heterogeneity }}=0.001\right)$; for Asian patients was $2.16(95 \% \mathrm{CI}, 1.76-2.66, P<0.001)$ with no heterogeneity $\left(\mathrm{I}^{2}=0.0 \%, \mathrm{P}_{\text {heterogeneity }}=0.844\right)($ Fig. 5$)$.

Sensitivity analysis. The sensitivity analysis was applied to detect the effects of each single study on the overall effect. The analysis did not detect a study that could alter significantly the combined results (Fig. 6). The results of the sensitivity analysis indicated that the pooled effect size of the meta-analysis results was stable and reliable.

\section{Publication bias}

The publication bias was assessed by the Begg's funnel plots and the Egger's test in the present study. The results indicated the publication bias existed among the studies $(p=0.018)$. Therefore, "trim and fill" analysis was further utilized, and the pooled HR of 1.569 (95\% CI, 1.276-1.930) remained statistically significant (Fig. 7),

\begin{tabular}{|c|c|c|}
\hline \multicolumn{2}{|c|}{ Study } & \multirow{2}{*}{$\begin{array}{l}\% \\
\text { Weight }\end{array}$} \\
\hline ID & $\mathrm{ES}(95 \% \mathrm{Cl})$ & \\
\hline \multicolumn{3}{|l|}{ LSCC } \\
\hline Elhadj (2019) & $1.76(0.56,5.58)$ & 1.18 \\
\hline $\mathrm{Li}(2011)$ & $1.89(1.09,3.28)$ & 5.21 \\
\hline Dong (2002) & $1.80(1.11,3.35)$ & 5.15 \\
\hline Pizem (2004) & $1.02(1.01,2.03)$ & 12.76 \\
\hline Subtotal $(I-$ squared $=42.3 \%, p=0.158)$ & $1.35(1.05,1.74)$ & 24.30 \\
\hline \multicolumn{3}{|l|}{ HNSCC } \\
\hline Erpolat (2012) & $0.37(0.08,1.66)$ & 0.70 \\
\hline Fiedler (2018) & $2.53(1.19,5.41)$ & 2.73 \\
\hline Farnebo (2013) & $2.40(1.24,4.65)$ & 3.60 \\
\hline Munscher (2019) & $1.37(1.09,1.72)$ & 30.22 \\
\hline Pickhard (2014) & $2.30(1.11,4.92)$ & 2.84 \\
\hline Subtotal $(I-$ squared $=55.3 \%, p=0.062)$ & $1.52(1.25,1.86)$ & 40.08 \\
\hline NPC & & \\
\hline $\operatorname{Jin}(2019)$ & $4.48(1.51,13.30)$ & 1.33 \\
\hline $\mathrm{Li}(2008)$ & $2.13(1.30,3.49)$ & 6.44 \\
\hline Xiang (2006) & $3.76(1.35,10.42)$ & 1.51 \\
\hline Yip (2006) & $2.30(1.10,4.90)$ & 2.82 \\
\hline Subtotal $(I-$ squared $=0.0 \%, p=0.540)$ & $2.53(1.76,3.62)$ & 12.10 \\
\hline \multicolumn{3}{|l|}{ oscc } \\
\hline Lin (2005) & $1.86(1.05,3.31)$ & 4.76 \\
\hline Tastekin (2017) & $4.92(2.58,9.40)$ & 3.76 \\
\hline $\operatorname{Kim}(2005)$ & $2.60(1.28,5.51)$ & 2.95 \\
\hline Zhang (2013) & $1.30(0.50,3.40)$ & 1.71 \\
\hline Freier (2007) & $2.47(1.02,5.96)$ & 2.02 \\
\hline \multicolumn{3}{|c|}{$2.71(1.46,5.10)$} \\
\hline \multicolumn{3}{|c|}{$2.04(1.01,4.10)$} \\
\hline $\operatorname{Kim}(2010)$ & $1.91(0.58,6.27)$ & 1.11 \\
\hline Subtotal $(I-$ squared $=7.7 \%, p=0.370)$ & $2.45(1.89,3.17)$ & 23.52 \\
\hline \multicolumn{3}{|l|}{ Heterogeneity between groups: $p=0.001$} \\
\hline Overall $(I-$ squared $=50.3 \%, p=0.005)$ & $1.76(1.55,1.99)$ & 100.00 \\
\hline$T$ & & \\
\hline .0752 & & \\
\hline
\end{tabular}

Fig. 4 Forest plot of OS in association with survivin in different types of HNSCC 


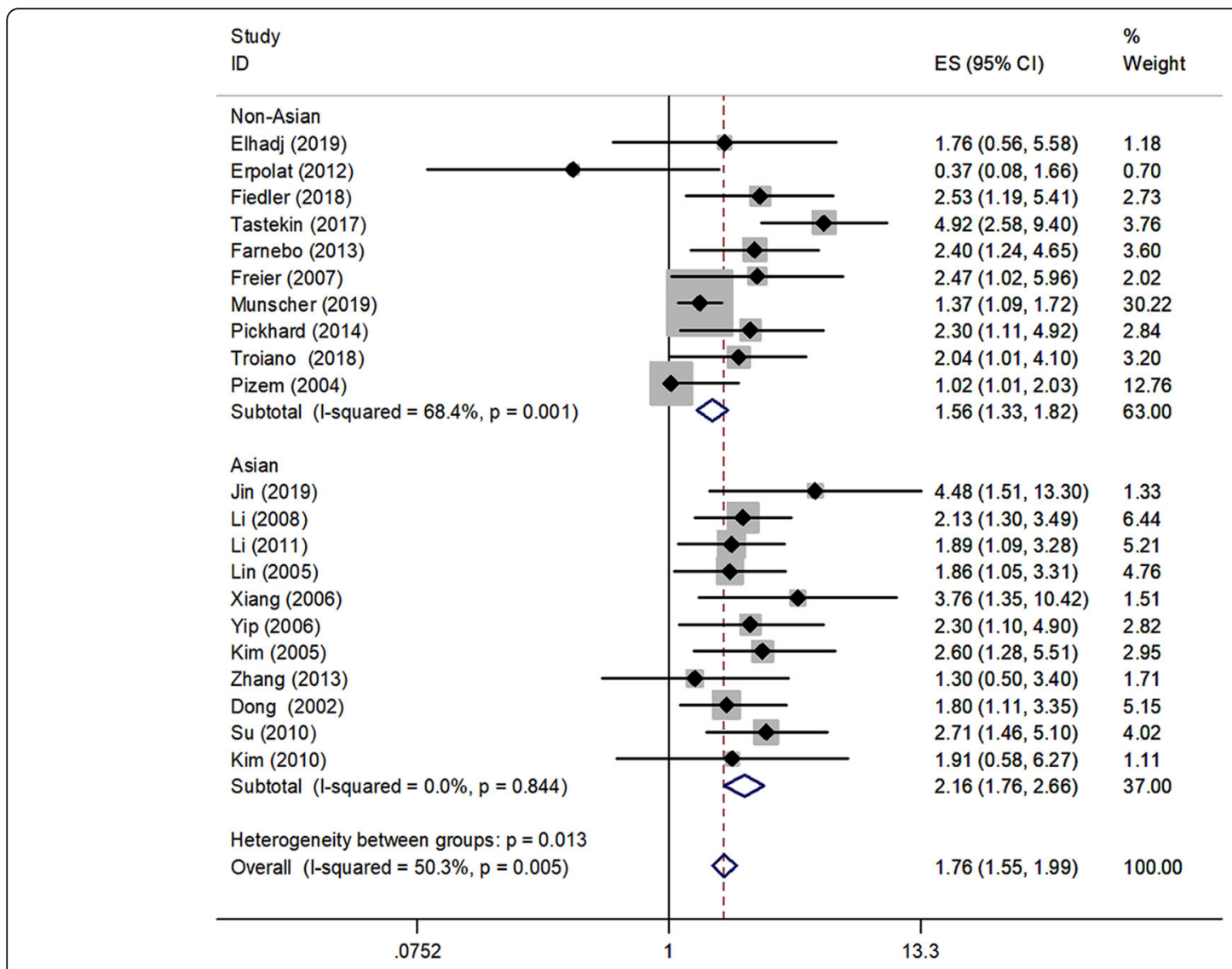

Fig. 5 Forest plot of OS in association with survivin in different types of geographic populations

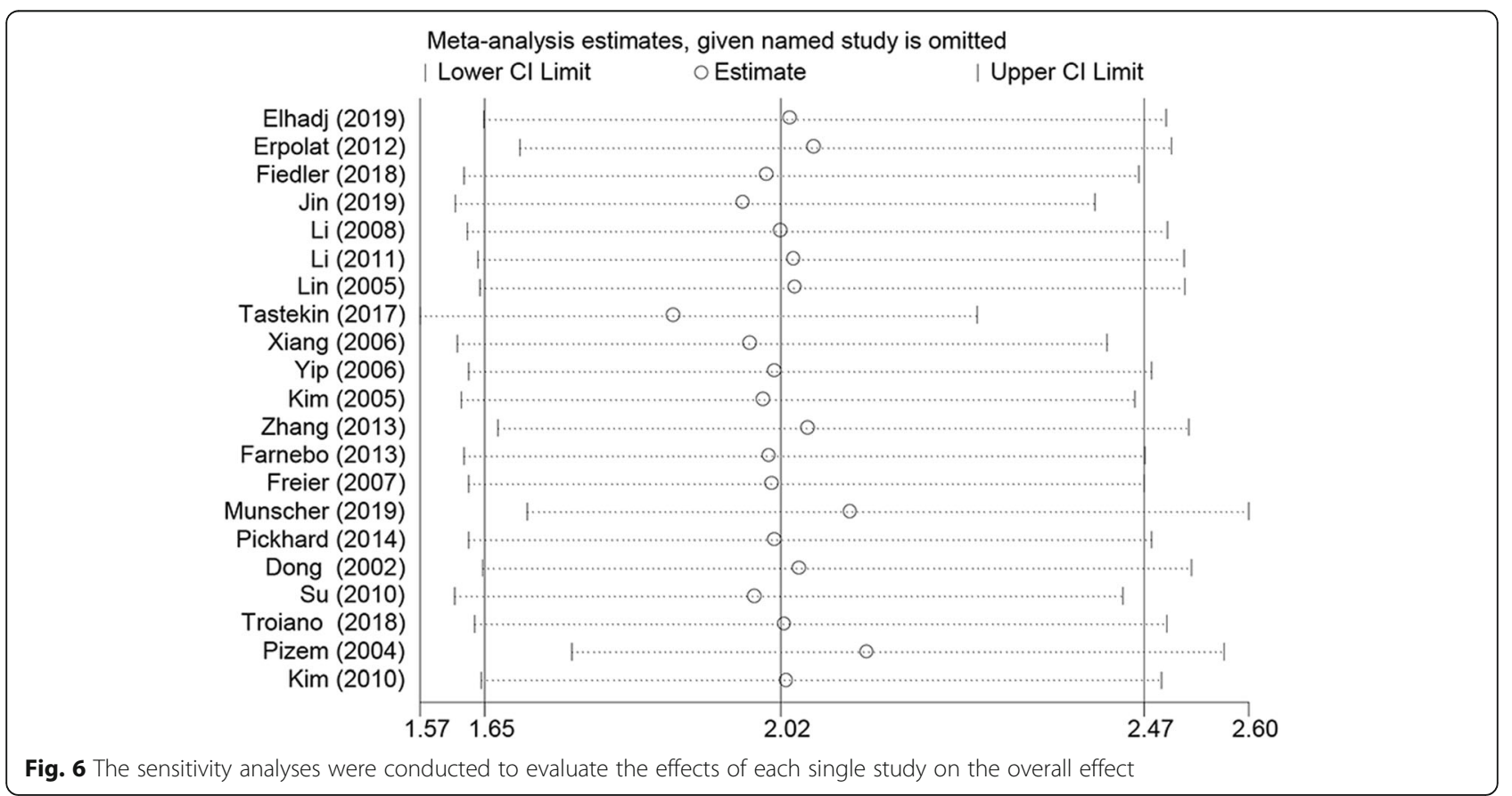


a

Begg's funnel plot with pseudo $95 \%$ confidence limits

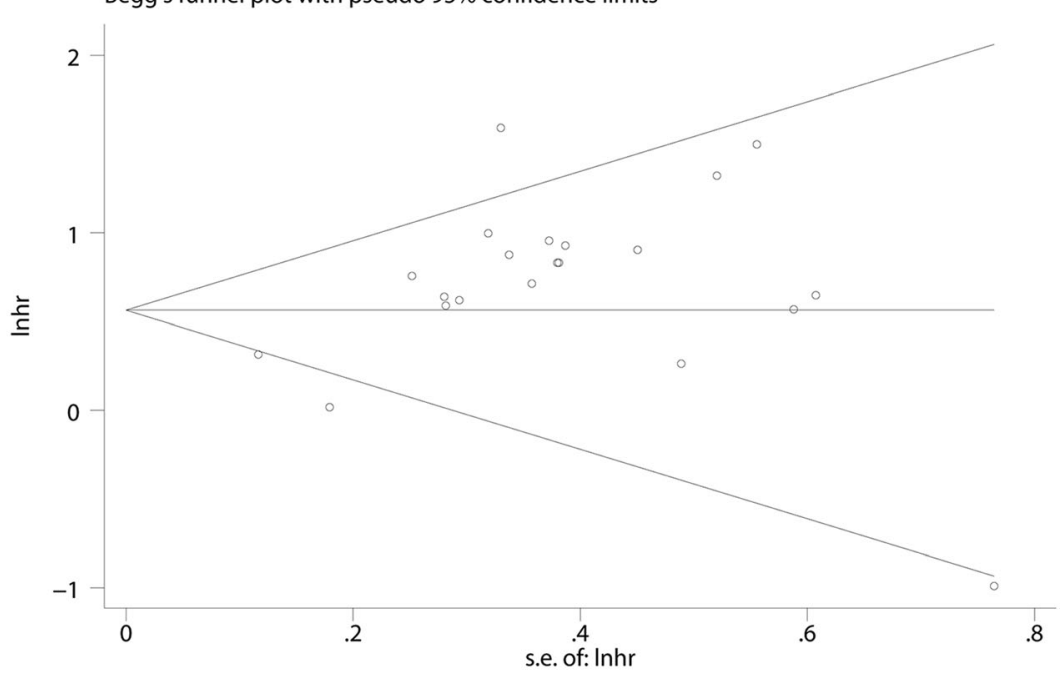

b Egger's publication bias plot

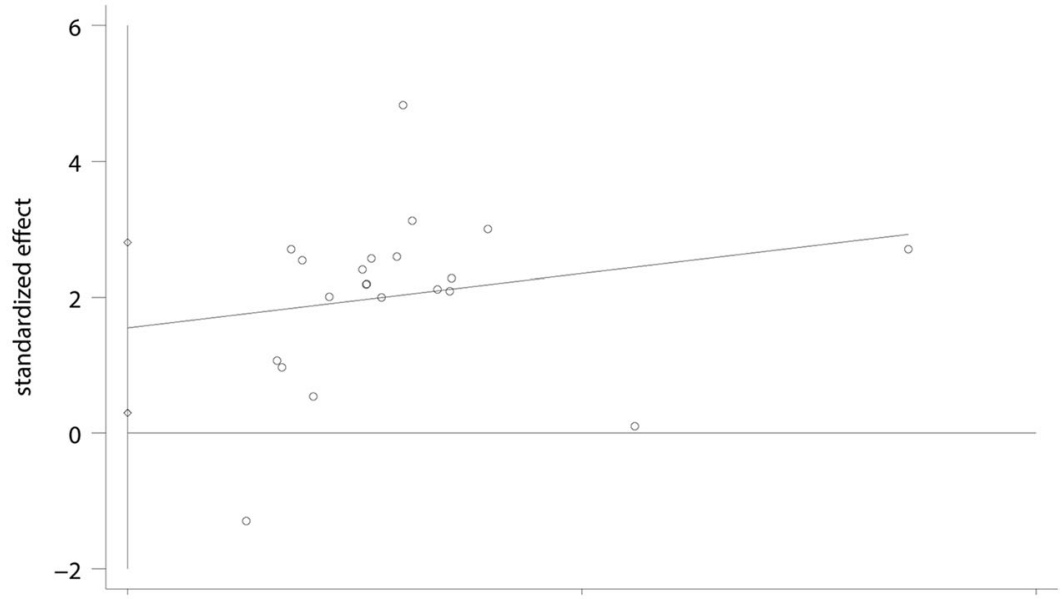

c

Filled funnel plot with pseudo $95 \%$ confidence limits

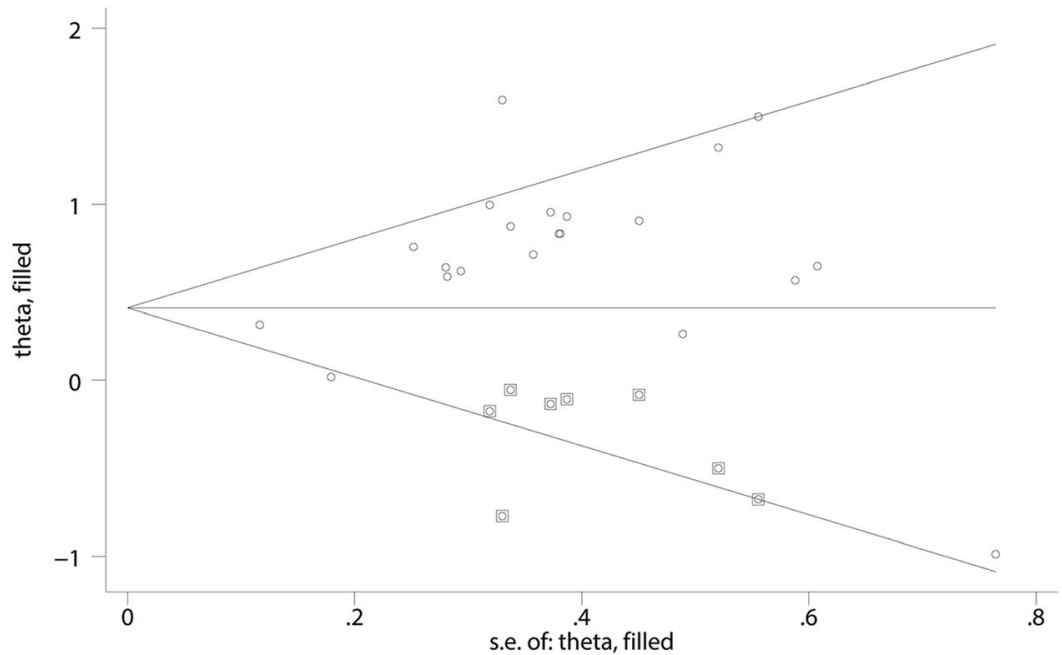

Fig. 7 Publication bias and trim and fill analysis of the enrolled analysis. a The Begg's funnel plots; b The Egger's test. c Trim and fill analysis 
therefore, the results of the present studies were robust in spite of the significant publication bias.

\section{Discussion}

Numerous studies have focused on the identification of new prognostic biomarkers that can be used for cancer monitoring and detection. An association between survivin expression and survival outcomes has been shown in HNSCC patients. The study by Fiedler et al. found that high survivin expression was significantly correlated to unfavorable DSS in HNSCC patients [19]. Kim et al. demonstrated that survivin overexpression had a significant negative effect on survival outcomes of OSCC patients [44]. However, contradictory results were reported by Hansson et al. that patients with strong nuclear survivin expression had better 5-year DFS compared with those with weak nuclear survivin expression [36]. Furthermore, Kim et al. found that Asian patients diagnosed with non-nasopharyngeal head and neck cancer tended to exhibit better OS than non-Asian patients [45]. The present study is the first meta-analysis including 28 published studies with 4891 patients to provide useful information for clinical decision-making in HNSCC. Survivin was significantly associated with poorer OS in HNSCC patients, with HR values of 2.02, similar results were found in subgroup analysis stratified by cancer type, such as LSCC, OSCC, NPC, etc. Significant correlation between survivin and shorter DFS/ DSS (HR 2.03/ HR 1.92, respectively) was also observed. Moreover, ethnicity-stratified analysis showed that survivin was significantly associated with poorer OS among both Asian and Non- Asian HNSCC patients (HR 2.16/ HR 1.56, respectively). These findings confirmed that survivin could be widely applied as diagnostic markers and therapeutic targets in HNSCC patients.

The prognostic value of survivin was investigated in HNSCC and gathering evidences suggested that survivin was an independent prognostic marker in HNSCC [46, 47]. Epigenetic modifications play roles in HNSCC by regulating survivin expression [48]. The hypomethylation of BIRC5 is an important step in OSCC tumorigenesis due to its GC-rich region [49]. p53 also participates in the survivin upregulation in OSCCs, positive correlation was found between survivin expression and p53 in both HNSCC and premalignant lesions by Khan et al. [50]. The survivin gene locus encodes for multiple alternative splice variants with several different functions and heterodimerization possibilities [51]. Twenty three HNSCC cell lines at different differentiation levels showed higher survivin expressed levels compared to a human cell line of epidermal keratinocyte [52]. Targeted therapies have produced striking benefits for patients with cancers. Survivin is preferable targets of therapeutic modalities, namely antisense nucleotides, small-molecule inhibitors, antitumor immunotherapy and RNA interference $[53,54]$. According to our results, the survivin inhibitors could be the therapeutics against the HNSCC. The expression of survivin in HNSCC patients represents an important factor that predicts poor prognosis and resistance to chemo- and radiotherapy. The clinical application of survivin as a molecular target in HNSCC therapy significantly benefits HNSCC patients.

However, the present meta-analysis also had several limitations. First, we found that different paper qualities and sample sizes across the studies might cause bias in the meta-analysis. Second, the approaches used to evaluate the survivin expression were different, such as antibodies characters in IHC and instruments used in RTPCR. Third, the cut-off value defining positive survivin expression varied among eligible studies (Table 1). Forth, our analysis might overestimate the prognostic significance of survivin to some degree due to the positive results reported in most of the including publications. Fifth, partial survival data of some including papers were extracted from Kaplan-Meier curves and may not as accurate as that obtained from original paper directly.

In conclusion, we searched the electronic databases and a total of 4891 patients in 28 studies were enrolled for meta-analysis, the results demonstrating that patients with survivin expression are more likely to have worse prognosis. Taken together, our meta-analysis results suggest that survivin gains a prognostic and diagnostic value for the HNSCC patients. However, more larger sample size studies are required to acquire a more representative and precise result.

\section{Supplementary Information}

The online version contains supplementary material available at https://doi. org/10.1186/s12885-021-08170-3.

Additional file 1: Table S1. Characteristics of the antibodies used in $\mathrm{IHC}$ in the including studies.

\section{Acknowledgements}

Not applicable.

\section{Authors' contributions}

$Y H$ and $L Z$ collected and analyzed the data, wrote the paper. LZ, YH and HX analyzed the data and wrote the paper. $L Z$ and $H X$ conceived and designed this study, analyzed the data, wrote the paper. All authors read and approved the final manuscript.

\section{Funding}

Not applicable.

\section{Availability of data and materials}

All data generated or analysed during this study are included in this published article [and its supplementary information files].

The data that support the findings of this study are available from the corresponding author upon reasonable request. 


\section{Declarations}

\section{Ethics approval and consent to participate}

Not applicable.

\section{Consent for publication}

Not applicable.

\section{Competing interests}

The author(s) declare(s) that they have no competing interests.

\section{Author details}

'Department of Otorhinolaryngology, Union Hospital, Ongji Medical College, Huazhong University of Science and Technology, Wuhan 430022, China. ${ }^{2}$ Department of Otorhinolaryngology, The Central Hospital of Wuhan, Huazhong University of Science and Technology, Wuhan 430000, China.

\section{Received: 5 December 2020 Accepted: 7 April 2021}

\section{Published online: 17 April 2021}

\section{References}

1. Jemal A, Siegel R, Xu J, Ward E. Cancer statistics, 2010. CA Cancer J Clin. 2010;60(5):277-300. https://doi.org/10.3322/caac.20073.

2. Leemans $\mathrm{CR}$, Braakhuis BJ, Brakenhoff $\mathrm{RH}$. The molecular biology of head and neck cancer. Nat Rev Cancer. 2011;11(1):9-22. https://doi.org/10.1038/ nrc2982.

3. Castellsagué X, Quintana MJ, Martínez MC, Nieto A, Sánchez MJ, Juan A, et al. The role of type of tobacco and type of alcoholic beverage in oral carcinogenesis. Int J Cancer. 2004;108(5):741-9. https://doi.org/10.1002/ijc.11 627.

4. Brockstein B, Haraf DJ, Rademaker AW, Kies MS, Stenson KM, Rosen F, et al. Patterns of failure, prognostic factors and survival in locoregionally advanced head and neck cancer treated with concomitant chemoradiotherapy: a 9-year, 337-patient, multi-institutional experience. Ann Oncol. 2004;15(8):1179-86. https://doi.org/10.1093/annonc/mdh308.

5. Ambrosini G, Adida C, Altieri DC. A novel anti-apoptosis gene, survivin, expressed in cancer and lymphoma. Nat Med. 1997;3(8):917-21. https://doi. org/10.1038/nm0897-917

6. Altieri DC. Survivin, versatile modulation of cell division and apoptosis in cancer. Oncogene. 2003;22(53):8581-9. https://doi.org/10.1038/sj.onc.12 07113.

7. Coumar MS, Tsai FY, Kanwar JR, Sarvagalla S, Cheung CHA. Treat cancers by targeting survivin: just a dream or future reality? Cancer Treat Rev. 2013; 39(7):802-11. https://doi.org/10.1016/j.ctrv.2013.02.002.

8. Niu TK, Cheng Y, Ren X, Yang JM. Interaction of Beclin 1 with survivin regulates sensitivity of human glioma cells to TRAlL-induced apoptosis. FEBS Lett. 2010;584(16):3519-24. https://doi.org/10.1016/j.febslet.2010.07.018.

9. O'Connor DS, Schechner JS, Adida C, Mesri M, Rothermel AL, Li F, et al. Control of apoptosis during angiogenesis by survivin expression in endothelial cells. Am J Pathol. 2000;156(2):393-8. https://doi.org/10.1016/ S0002-9440(10)64742-6.

10. Dickersin K, Scherer R, Lefebvre C. Identifying relevant studies for systematic reviews. Bmj. 1994;309(6964):1286-91. https://doi.org/10.1136/bmj.309. 6964.1286

11. Parmar MK, Torri V, Stewart L. Extracting summary statistics to perform meta-analyses of the published literature for survival endpoints. Stat Med. 1998;17(24):2815-34. https://doi.org/10.1002/(SICI)1097-0258(19981230)17:24 $<2815:: A I D-S I M 110>3.0 . C O ; 2-8$.

12. Wells GA, et al. The Newcastle-Ottawa Scale (NOS) for assessing the quality of nonrandomised studies in meta-analyses. Oxford; 2000.

13. Stang A. Critical evaluation of the Newcastle-Ottawa scale for the assessment of the quality of nonrandomized studies in meta-analyses. Eur J Epidemiol. 2010;25(9):603-5. https://doi.org/10.1007/s10654-010-9491-z.

14. Sauerbrei W, Taube SE, MCShane LM, Cavenagh MM, Altman DG. Reporting recommendations for tumor marker prognostic studies (REMARK): an abridged explanation and elaboration. J Natl Cancer Inst. 2018;110(8):80311. https://doi.org/10.1093/jnci/djy088

15. Extracting summary statistics to perform meta-analysis of the published literature for survival endpoints by M. Parmar, V. Torri and L. Stewart, Statistics in Medicine 1998; 17: 2815-2834 (p 1817). Statistics in Medicine, 2010. 23(11): p. 1817-1817.
16. Higgins JP, Thompson SG, Deeks JJ, Altman DG. Measuring inconsistency in meta-analyses. Bmj. 2003;327(7414):557-60. https://doi.org/10.1136/bmj.327. 7414.557

17. Ben Elhadj $M$, et al. Expression Profile of Survivin and p16 in Laryngeal Squamous Cell Carcinoma: Contribution of Tunisian Patients. Ear Nose Throat J. 2021;100(1):NP7-15.

18. Erpolat OP, Gocun PU, Akmansu M, Karakus E, Akyol G. High expression of nuclear survivin and Aurora B predicts poor overall survival in patients with head and neck squamous cell cancer. Strahlenther Onkol. 2012;188(3):24854. https://doi.org/10.1007/s00066-011-0042-7.

19. Fiedler M, Weber F, Hautmann MG, Haubner F, Reichert TE, Klingelhöffer C, et al. Biological predictors of radiosensitivity in head and neck squamous cell carcinoma. Clin Oral Investig. 2018;22(1):189-200. https://doi.org/10.1 007/s00784-017-2099-X.

20. Jin PY, Zheng ZH, Lu HJ, Yan J, Zheng GH, Zheng YL, et al. Roles of $\beta$ catenin, TCF-4, and survivin in nasopharyngeal carcinoma: correlation with clinicopathological features and prognostic significance. Cancer Cell Int 2019;19(1):48. https://doi.org/10.1186/s12935-019-0764-7.

21. Li YH, Hu CF, Shao Q, Huang MY, Hou JH, Xie D, et al. Elevated expressions of survivin and VEGF protein are strong independent predictors of survival in advanced nasopharyngeal carcinoma. J Transl Med. 2008;6(1):1. https:// doi.org/10.1186/1479-5876-6-1.

22. Li DW, et al. Effect of apoptotic and proliferative indices, P-glycoprotein and survivin expression on prognosis in laryngeal squamous cell carcinoma. Med Oncol. 2011;28(Suppl 1):S333-40.

23. Lin CY, Hung HC, Kuo RC, Chiang CP, Kuo MYP. Survivin expression predicts poorer prognosis in patients with areca quid chewing-related oral squamous cell carcinoma in Taiwan. Oral Oncol. 2005;41(6):645-54. https:// doi.org/10.1016/j.oraloncology.2005.02.009.

24. Lo Muzio L, et al. Survivin as prognostic factor in squamous cell carcinoma of the oral cavity. Cancer Lett. 2005;225(1):27-33. https://doi.org/10.1016/j.ca nlet.2004.11.024.

25. Preuss SF, Weinell A, Molitor M, Stenner M, Semrau R, Drebber U, et al. Nuclear survivin expression is associated with HPV-independent carcinogenesis and is an indicator of poor prognosis in oropharyngeal cancer. Br J Cancer. 2008;98(3):627-32. https://doi.org/10.1038/sj.bjc.6604192.

26. Tastekin E, Caloglu VY, Durankus NK, Sut N, Turkkan G, Can N, et al. Survivin expression, HPV positivity and microvessel density in oropharyngeal carcinomas and relationship with survival time. Arch Med Sci. 2017;13(6): 1467-73. https://doi.org/10.5114/aoms.2015.56616.

27. Wang HY, Sun BY, Zhu ZH, Chang ET, To KF, Hwang JSG, et al. Eightsignature classifier for prediction of nasopharyngeal [corrected] carcinoma survival. J Clin Oncol. 2011;29(34):4516-25. https://doi.org/10.1200/JCO.201 0.33.7741.

28. Xiang $Y$, Yao H, Wang S, Hong M, He J, Cao S, et al. Prognostic value of Survivin and Livin in nasopharyngeal carcinoma. Laryngoscope. 2006;116(1): 126-30. https://doi.org/10.1097/01.mlg.0000187392.87904.35.

29. Yip KW, Shi W, Pintilie M, Martin JD, Mocanu JD, Wong D, et al. Prognostic significance of the Epstein-Barr virus, p53, Bcl-2, and survivin in nasopharyngeal cancer. Clin Cancer Res. 2006;12(19):5726-32. https://doi. org/10.1158/1078-0432.CCR-06-0571.

30. Zhao H, Ren J, Zhuo X, Ye H, Zou J, Liu S. Prognostic significance of Survivin and CD44v6 in laryngeal cancer surgical margins. J Cancer Res Clin Oncol. 2008;134(10):1051-8. https://doi.org/10.1007/s00432-008-0391-5.

31. Dong $Y$, Sui L, Watanabe $Y$, Sugimoto K, Tokuda M. Survivin expression in laryngeal squamous cell carcinomas and its prognostic implications. Anticancer Res. 2002;22(4):2377-83.

32. Kim MJ, Lim KY, Kim JW, Nam IW, Lee JH, Myoung H. Stage and mRNA expression of survivin in lymph node as prognostic indicators in patients with oral squamous cell carcinoma. Cancer Lett. 2005;224(2):253-61. https:// doi.org/10.1016/j.canlet.2005.01.009.

33. Zhang $M$, et al. Prognostic significance of $p 21$, p27 and survivin protein expression in patients with oral squamous cell carcinoma. Oncol Lett. 2013; 6(2):381-6. https://doi.org/10.3892/ol.2013.1381.

34. Farnebo L, Tiefenböck K, Ansell A, Thunell LK, Garvin S, Roberg K. Strong expression of survivin is associated with positive response to radiotherapy and improved overall survival in head and neck squamous cell carcinoma patients. Int J Cancer. 2013;133(8):1994-2003. https://doi.org/10.1002/ijc.282 00.

35. Freier K, Pungs $S$, Sticht $C$, Flechtenmacher $C$, Lichter $P$, Joos $S$, et al. High survivin expression is associated with favorable outcome in advanced 
primary oral squamous cell carcinoma after radiation therapy. Int J Cancer 2007:120(4):942-6. https://doi.org/10.1002/ijc.22380.

36. Tiefenböck-Hansson K, Haapaniemi A, Farnebo L, Palmgren B, Tarkkanen J, Farnebo M, et al. WRAP53 $\beta$, survivin and p16INK4a expression as potential predictors of radiotherapy/chemoradiotherapy response in T2NO-T3NO glottic laryngeal cancer. Oncol Rep. 2017;38(4):2062-8. https://doi.org/10.3 892/or.2017.5898.

37. Münscher A, Prochnow S, Gulati A, Sauter G, Lörincz B, Blessmann M, et al. Survivin expression in head and neck squamous cell carcinomas is frequent and correlates with clinical parameters and treatment outcomes. Clin Oral Investig. 2019;23(1):361-7. https://doi.org/10.1007/s00784-018-2444-8.

38. Pickhard A, Gröber S, Haug AK, Piontek G, Wirth M, Straßen U, et al. Survivin and pAkt as potential prognostic markers in squamous cell carcinoma of the head and neck. Oral Surg Oral Med Oral Pathol Oral Radiol. 2014;117(6): 733-42. https://doi.org/10.1016/.0000.2014.02.005.

39. Su L, et al. Up-regulation of survivin in oral squamous cell carcinoma correlates with poor prognosis and chemoresistance. Oral Surg Oral Med Oral Pathol Oral Radiol Endod. 2010;110(4):484-91.

40. Troiano $\mathrm{G}$, et al. Integrative Histologic and Bioinformatics Analysis of BIRC5/ Survivin Expression in Oral Squamous Cell Carcinoma. Int J Mol Sci. 2018; 19(9):2664.

41. Pizem J, Cör A, Gale N. Survivin expression is a negative prognostic marker in laryngeal squamous cell carcinoma and is associated with p53 accumulation. Histopathology. 2004;45(2):180-6. https://doi.org/10.1111/j.13 65-2559.2004.01925.x.

42. Marioni G, Staffieri A, Lionello M, Tealdo G, Staffieri C, Giacomelli L, et al. Relationship between anti-apoptotic proteins survivin and $\mathrm{BCl}-2$, and response to treatment in patients undergoing post-operative RT for laryngeal cancer: a pilot study. J Oral Pathol Med. 2013;42(4):339-44. https:// doi.org/10.1111/jop.12020

43. Marioni G, Ottaviano G, Marchese-Ragona R, Fasanaro E, Tealdo G, Zanotti C, et al. Nuclear survivin expression correlates with endoglin-assessed microvascularisation in laryngeal carcinoma. J Clin Pathol. 2017;70(12):10337. https://doi.org/10.1136/jclinpath-2016-204230.

44. Kim YH, et al. Evaluation of survivin as a prognostic marker in oral squamous cell carcinoma. J Oral Pathol Med. 2010;39(5):368-75.

45. Kim JD, Chang JT, Moghaddamjou A, Kornelsen EA, Ruan JY, Olson RA, et al. Asian and non-Asian disparities in outcomes of non-nasopharyngeal head and neck cancer. Laryngoscope. 2017;127(11):2528-33. https://doi.org/10.1 002/lary.26603.

46. Riedl J, Posch F, Königsbrügge O, Lötsch F, Reitter EM, Eigenbauer E, et al. Red cell distribution width and other red blood cell parameters in patients with cancer: association with risk of venous thromboembolism and mortality. PLoS One. 2014;9(10):e111440. https://doi.org/10.1371/journal. pone.0111440

47. Yilmaz A, Malya F, Ozturk G, Citgez B, Ozdenkaya Y, Ersavas C, et al. Effect of pre-operative red blood cell distribution on cancer stage and morbidity rate in patients with pancreatic cancer. Int J Clin Exp Med. 2014;7(9):3072-5.

48. Lyu H, Huang J, He Z, Liu B. Epigenetic mechanism of survivin dysregulation in human cancer. Sci China Life Sci. 2018;61(7):808-14. https://doi.org/10.1 007/s11427-017-9230-2.

49. Chen YK, Hsue SS, Lin LM. Survivin expression is regulated by an epigenetic mechanism for DMBA-induced hamster buccal-pouch squamous-cell carcinomas. Arch Oral Biol. 2005;50(6):593-8. https://doi.org/10.1016/j.a rchoralbio.2004.11.011.

50. Khan Z, Tiwari RP, Mulherkar R, Sah NK, Prasad GBKS, Shrivastava BR, et al. Detection of survivin and p53 in human oral cancer: correlation with clinicopathologic findings. Head Neck. 2009;31(8):1039-48. https://doi.org/1 0.1002/hed.21071

51. De Maria $\mathrm{S}$, et al. Survivin gene-expression and splicing isoforms in oral squamous cell carcinoma. J Cancer Res Clin Oncol. 2009;135(1):107-16. https://doi.org/10.1007/s00432-008-0433-z.

52. de Maria S, Lo Muzio L, Braca A, Rega P, Cassano A, Vinella A, et al. Survivin promoter -31G/C polymorphism in oral cancer cell lines. Oncol Lett. 2011; 2(5):935-9. https://doi.org/10.3892/ol.2011.358.

53. Cheng SM, Chang YC, Liu CY, Lee JYC, Chan HH, Kuo CW, et al. YM155 down-regulates survivin and XIAP, modulates autophagy and induces autophagy-dependent DNA damage in breast cancer cells. Br J Pharmacol. 2015;172(1):214-34. https://doi.org/10.1111/bph.12935.

54. Santarelli A, et al. Survivin-Based Treatment Strategies for Squamous Cell Carcinoma. Int J Mol Sci. 2018;19(4):971.

\section{Publisher's Note}

Springer Nature remains neutral with regard to jurisdictional claims in published maps and institutional affiliations.
Ready to submit your research? Choose BMC and benefit from:

- fast, convenient online submission

- thorough peer review by experienced researchers in your field

- rapid publication on acceptance

- support for research data, including large and complex data types

- gold Open Access which fosters wider collaboration and increased citations

- maximum visibility for your research: over $100 \mathrm{M}$ website views per year

At BMC, research is always in progress.

Learn more biomedcentral.com/submissions 